\title{
DIVERSIDADE E EDUCAÇÃO - O QUE TRANSITA PELA EDUCAÇÃO BÁSICA?
}

Caríssimos/as Leitores/as,

De acordo com o perfil de uma revista multidisciplinar, a diversidade se faz presente, mais uma vez, nesta décima sexta edição de e-Mosaicos. As temáticas que compõem esta edição apresentam a escola em sua diversidade e multiplicidade de abordagens e, para além dela, as perspectivas extensionistas e não formais que se inserem nos espaços formativos, permitindo-nos dialogar com os diferentes saberesfazeres que transitam no espaço escolar.

Nesta edição, composta de 14 artigos organizados em duas seções, os diálogos possibilitam pensar sobre a escola em seus diferentes campos de atuação e áreas de conhecimento, além das interfaces entre universidade e escola.

A seção Artigos está composta de 11 artigos. O primeiro artigo, de autoria de Paula Almeida de Castro e de Cleidiane de Oliveira Sousa Alves, aborda a necessária política de formação docente dentro do contexto da política de formação de professores em uma perspectiva inclusiva. A experimentação como contribuição para o ensino de Química e a leitura dos licenciandos é o tema do artigo de autoria de Letícia do Prado e Marcelo Carbone Carneiro. A importância da extensão universitária na formação inicial docente na área de Educação de Jovens e Adultos é o tema trazido por Ana Paula Abreu Moura que busca "construir um diálogo entre as Diretrizes da Extensão Universitária". O ensino de Geografia entra em cena com o artigo de Telma Mendes Silva e Priscila Carvalho Leibão, considerando as aulas de campo como importantes aliadas metodológicas e buscando contribuir com os professores de Geografia com o uso dessa metodologia. Ainda em relação ao ensino da Geografia, Eunice Isaías da Silva discute a linguagem de quadrinhos no processo-aprendizagem abordando o estudo do lugar geográfico. O artigo "Ambiente, tecnologia e educação: da teoria à prática", de autoria de Reis Friede, Edna Viveiros, Kátia Avelar, Carlos de Vasconcellos e Maria Geralda de Miranda analisa o ambiente como "um dos fatores que influencia no processo de ensino-aprendizagem", considerando a importância da interação entre diferentes espaços. A modalidade Educação de Jovens e Adultos também se faz presente no artigo de autoria de Marcus Tovar, Augusto e Victor del Rio trazendo resultados de pesquisa desenvolvida no Programa de Educação de Jovens e Adultos da SME/RJ e que buscou oferecer ferramentas para o uso do ensino colaborativo no ensino de Matemática. Renato Emerson, Gabriel Corrêa e Ronald Santos abordam a Lei no 10.639/2003 e sua implementação a partir de oficinas realizadas pelo Núcleo de Pesquisa e Estudos em Geografia, Relações Raciais e Movimentos Sociais da FFP/UERJ. Rogério Mendes Lima e Fernanda dos Santos Valim da Silva apresentam resultado de pesquisa de mestrado que discute a implementação de práticas pedagógicas interculturais nas aulas de Língua Portuguesa. Exclusão digital e educação é tema do décimo artigo, de autoria de Adriane Matos de Araujo e Carmem 
DOI: 10.12957/e-mosaicos.2018.39721

Lúcia Guimarães de Mattos. Elen Vieira Oliveira e Luiz Antônio Gomes Senna propõem uma reflexão sobre as relações entre o ENEM, o letramento e a exclusão escolar.

A seção especial Sociedade e Educação Contemporânea - desafios e propostas apresenta três artigos Mônica Almeida apresenta "argumentos favoráveis à aplicação de políticas de ação afirmativa como forma de enfrentamento das desigualdades sociais". Em "Pensando culturas ameríndias: experiências de um projeto de ensino e estranhamentos", Danielle Bastos analisa projeto sobre o ensino de culturas ameríndias em Instituto de Aplicação do Rio de Janeiro. O último artigo da seção, de autoria de Cheila Santos e de Andrea Fernandes apresenta resultados de pesquisa que discute os sentidos atribuídos ao livro didático do PNLD/EJA por estudantes de rede pública municipal de ensino, na modalidade Educação de Jovens e Adultos.

Desejamos a todos e a todas, mais uma vez, excelente leitura e agradecemos pelo envio dos artigos.

Andrea da Paíxão Fernandes

Editora da e-Mosaicos - Revista Multidisciplinar de Ensino, Pesquisa, Extensão e Cultura do Instituto de Aplicação Fernando Rodrigues da Silveira (CAp-UERJ) 